de Jardim Alegre/PR. Revista Eletrônica Interdisciplinar, v. 6, n. 1, p. 62-72, jan.-jun., 2013. Disponível em: $<$ http://revistas.ufpr.br/diver/article/ view/33934/21168>. Acesso em: 02 ago. 2017.

UENO, V. A.; NEVES, M. Corrêa; QUEIROGA, Joel Leandro de; RAMOS FILHO, Luiz Octávio; OLIVEIRA, Laíssa Pacheco de. Estratégias de comercialização da agricultura familiar: estudo de caso em assentamentos rurais do estado de São Paulo. In: Simpósio sobre reforma agrária e questões rurais, 7., 2016, Araraquara - SP. Anais eletrônicos... Araraquara - SP UNIARA, 2016. Disponível em: <https://www.alice.cnptia.embrapa.br/ alice/handle/doc/1065665>. Acesso em: 09 ago. 2017.

VASCONCELOS, M. J. C. S.; BARBOSA JÚNIOR, Djalma Adão; STURZA, José Adolfo Iriam. Caracterização das atividades agroindustriais em assentamentos rurais vinculados a Associação Dando as Mãos no estado de Mato Grosso. In: Encontro Nacional de Geografia Agrária, 13., São Cristóvão - SE. Anais eletrônicos... São Cristóvão - SE: UFS, 2016. Disponível em: $<$ http://enga.com.br/anais/index.php $>$. Acesso em: 10 ago. 2017.

VERDEJO, M. E. Diagnóstico rural participativo: guia prático DRP Revisão e adaptação Décio Cotrim e Ladjane Ramos. Ministério do Desenvolvimento Agrário, Secretaria da Agricultura Familiar, Brasília, mar. 2006. Disponível em: <http://www.mda.gov.br/sitemda/sites/ sitemda/files/user_arquivos_64/pageflip-2583697-3759191-DRP_-_Guia_ prtico-2649689.pdf $>$. Acesso em: 28 abr. 2017.

VERGES, N. M. Financiamento do setor rural: uma análise dos programas Procera e Pronaf e o caso dos assentamentos rurais do Pontal do Paranapanema - SP. Agrária, São Paulo, n. 15, p. 45-70, 2011.

\section{DESAFIOS DO PROGRAMA NACIONAL DE ALIMENTACÃO ESCOLAR (PNAE) COMO INSTRUMENTO DE FORTALECIMENTO DA AGRICULTURA FAMILIAR EM PEQUENOS MUNICÍPIOS}

\author{
Edmilson Carlos de Almeida Lopes Junior ${ }^{l}$ \\ André de Camargo Macedo ${ }^{2}$ \\ Ricardo Serra Borsatto ${ }^{3}$ \\ Leandro de Lima Santos ${ }^{4}$ \\ Vanilde Ferreira de Souza-Esquerdo
}

RESUMO: A partir da promulgação da Lei 11.947/2009, as compras de alimentos destinadas para a alimentação escolar passaram a servir como instrumento de fortalecimento da agricultura familiar. Desde então, ficou estabelecido que ao menos $30 \%$ dos recursos destinados para o Programa Nacional de Alimentação Escolar (PNAE) fossem utilizados na compra de alimentos produzidos pela agricultura familiar. Esse trabalho analisou a operacionalização desse programa em três municípios da região Sudoeste Paulista, objetivando compreender as dificuldades que pequenos municípios enfrentam em sua execução. Os resultados apontaram que, apesar de o programa ser considerado de grande relevância pelos atores locais, diferentes dificuldades emergem em função dos arranjos que se estabelecem em cada município. A pesquisa revelou que o comprometimento dos gestores públicos locais na promoção do diálogo entre os atores envolvidos na execução do programa pode ser considerado o fator decisivo para o sucesso do programa.

${ }^{1}$ Centro de Ciências da Natureza, Universidade Federal de São Carlos (CCN/UFSCar). Graduando em Engenharia Agronômica. Bolsista PIBIC/CNPq/UFSCar. e-mail: ecalopesjr@gmail.com.

${ }^{2}$ Centro de Ciências da Natureza, Universidade Federal de São Carlos (CCN/UFSCar). Graduando em Engenharia Agronômica. e-mail: andre_macedo11@hotmail.com.

${ }^{3}$ Centro de Ciências da Natureza (CCN/UFSCar), Programa de Pós-Graduação em Agroecologia e Desenvolvimento Rural Universidade Federal de São Carlos (PPGADR/UFSCar), Professor Adjunto. e-mail ricardo.borsatto@ufscar.br.

${ }^{4}$ Centro de Ciências da Natureza, Universidade Federal de São Carlos (CCN/UFSCar), Professor Adjunto. e-mail: leandrodelima@ufscar.br.

${ }^{5}$ Faculdade de Engenharia Agrícola, Universidade Estadual de Campinas (FEAGRI/UNICAMP), Programa de Pós-Graduação em Agroecologia e Desenvolvimento Rural Universidade Federal de São Carlos (PPGADR UFSCar), Professor Doutora. e-mail: vanilde.esquerdo@feagri.unicamp.br. 
Palavras-Chave: políticas públicas; desenvolvimento rural; cadeias agroalimentares

ABSTRACT : Since the enactment of Law 11.947 / 2009, school feeding purchases have started to serve as an instrument for strengthening family farming. Since then, it was established that at least $30 \%$ of the resources allocated to the Brazilian School Feeding Program (PNAE) should be used to purchase food produced by family farming. This work analyzes the operationalization of this program in three municipalities of the State of São Paulo, aiming to understand the difficulties that small municipalities face in their execution. The results pointed out that, although the program is considered of great relevance by the local actors, different difficulties emerge due to the arrangements established in each municipality. The research revealed that the commitment of local public authorities in promoting dialogue among the actors involved in the execution of the program could be considered the decisive factor for the success of the program.

KEYWORDS: public policy; rural development; agri-food chains.

\section{INTRODUÇÃo}

A agricultura familiar e camponesa brasileira historicamente não foi contemplada com políticas públicas que promovessem o seu desenvolvimento. Essa situação começa a mudar a partir de meados da década de 1990 com a criação do Programa Nacional de Fortalecimento da Agricultura Familiar (PRONAF), considerado como um dos primeiros programas voltados exclusivamente para esse segmento social. A partir de 2003, no decorrer dos governos Lula e Dilma, a agricultura familiar e camponesa brasileira passou a ser beneficiária de um rol de programas e políticas cujo objetivo foi o de promover o seu desenvolvimento e fortalecimento. Apesar da importância desse esforço institucional, ainda são limitadas as pesquisas que visaram compreender as dificuldades que essas políticas e programas enfrentam em expressar o seu potencial.

Assim, a pesquisa aqui apresentada estudou um desses programas, a utilização da merenda escolar para a aquisição de alimentos da agricultura familiar. Com a promulgação da Lei 11.947/2009 ficou estabelecido que ao menos 30\% dos recursos destinados para o Programa Nacional de Alimentação Escolar (PNAE) fossem utilizados na compra de alimentos produzidos pela agricultura familiar, preferencialmente local ou regional.
Assim, atualmente, além de garantir a segurança alimentar e nutricional de estudantes de escolas públicas, o PNAE tem promovido a inserção produtiva da agricultura familiar pela criação de uma forma de mercado institucional (BRASIL, 2009).

Baccarin et al. (2017) demonstram que existe grande discrepância no volume adquirido de alimentos da agricultura familiar entre os estados, enquanto os municípios do Rio Grande do Sul gastaram em 2014 aproximadamente $40 \%$ dos repasses do Fundo Nacional de Desenvolvimento da Educação (FNDE), destinados ao PNAE, com aquisição de alimentos da agricultura familiar; no Amapá, esse percentual ficou ao redor de 4,2\%. Mesma situação pode ser verificada entre os municípios paulistas, onde, se por um lado diversos não adquiriram produtos da agricultura familiar, por outro, alguns adquiriram um valor maior do que o do repasse do FNDE.

Pesquisas têm apontado as dificuldades que alguns municípios têm enfrentado para cumprir com a legislação e utilizar os recursos do PNAE para adquirir alimentos da agricultura familiar local (PROCÓPIO, OLIVEIRA e BORSATTO, 2015; SOUZA-ESQUERDO e BERGAMASCO, 2014)

Dentro desse contexto, esse trabalho teve o objetivo de contribuir na compreensão dos fatores que limitam que o PNAE cumpra o seu potencial de promover o desenvolvimento da agricultura familiar. Para tanto, apresenta os resultados de estudos realizados em três municípios da região Sudoeste Paulista, nos quais foram estudados e identificados entraves enfrentados pelos atores sociais locais na execução do programa.

\section{O PROGRAMA NACIONAL DE ALIMENTAÇÃo ESCOLAR}

baseando-se nos dados do Censo Agropecuário de 2006, Kageyama, Bergamasco e Oliveira, (2013) identificaram no Brasil 4,3 milhões de estabelecimentos agropecuários conduzidos por agricultores familiares, 0 que correspondia a $84,4 \%$ dos estabelecimentos agropecuários, ocupando $24,3 \%$ da área total de produção. A importância da agricultura familiar é demonstrada quando apesar de ocupar apenas 1/4 da área de produção, ela é responsável por aproximadamente metade do valor de produção na agricultura e por empregar 13,5 milhões de pessoas, correspondendo a 74\% da mão-de-obra no meio rural.

Diferentemente da agricultura empresarial que há décadas é beneficiada por políticas de apoio à comercialização de sua produção, como a Política de Garantia de Preços Mínimos (PGPM), a agricultura familiar somente passa a ser contemplada com um programa nesse sentido quando, através Programa 
Fome Zero, criou-se o Programa de Aquisição de Alimentos (PAA).

O PAA emergiu como resultado da confluência de dois importantes debates ocorridos durante a década de 1990 no Brasil. O primeiro tinha como questões centrais o combate à fome e a garantia da segurança alimentar e nutricional à população brasileira. $\mathrm{O}$ segundo debate era direcionado ao reconhecimento da importância da agricultura familiar como categoria social pelas políticas governamentais. O PAA atua paralelamente nestas duas frentes, apoiando o desenvolvimento rural ao estabelecer um mercado garantido com preços pré-definidos para os produtos da agricultura familiar, e garantindo a segurança alimentar e nutricional de populações em situação de vulnerabilidade social pela distribuição gratuita desses alimentos a essas populações (BALSADI, 2004; GRISA e ZIMMERMANN, 2015; MALUF et al., 2015; ROCHA, 2009).

Seguindo a frente aberta pelo PAA de utilizar as compras públicas como instrumento para fortalecer a agricultura familiar, em 2009, o PNAE, programa já existente de alimentação de estudantes da esfera pública, passa a apoiar a agricultura familiar quando determina que as entidades executoras devem utilizar no mínimo 30\% do valor remetido pelo FNDE para aquisição de gêneros alimentícios de fornecedores que se enquadrem nesta categoria social (BRASIL, 2009).

Art. 14. Do total dos recursos financeiros repassados pelo FNDE, no âmbito do PNAE, no mínimo 30\% (trinta por cento) deverão ser utilizados na aquisição de gêneros alimentícios diretamente da agricultura familiar e do empreendedor familiar rural ou de suas organizações, priorizando-se os assentamentos da reforma agrária, as comunidades tradicionais indígenas e comunidades quilombolas. $\S 1$ o A aquisição de que trata este artigo poderá ser realizada dispensando-se o procedimento licitatório, desde que os preços sejam compatíveis com os vigentes no mercado local, observandose os princípios inscritos no art. 37 da Constituição Federal, e os alimentos atendam às exigências do controle de qualidade estabelecidas pelas normas que regulamentam a matéria.

O órgão gestor do programa é o Ministério da Educação, tendo como fonte de recursos o Fundo Nacional de Desenvolvimento da Educação (FNDE). A compra dos alimentos oriundos da agricultura familiar pode ser realizada em nível municipal através de chamadas públicas, sem a necessidade de licitação, para tanto, os preços devem ser compatíveis com o mercado local. Inicialmente a Lei ${ }^{\circ} 11.947$ de 2009 previa um limite de $\mathrm{R} \$ 9.000,00$ por agricultor/ano. Esse valor foi alterado em 2012 e o limite passou para R $\$ 20.000,00$ por agricultor/ano, aumentando o impacto desse programa (BRASIL, 2012).

As compras pelo PNAE são feitas de através das Entidades Executoras (EEx) de forma centralizada, quando são realizadas pelas secretarias estaduais de educação ou pelas prefeituras e escolas federais, ou decentralizadas, através das Unidades Executoras (UEx), quando realizada pelas escolas. Contudo, os recursos são destinados às EEx, que optam ou não pela descentralização.

Para operacionalização do Artigo 14 da Lei 11.947/2009, as prefeituras, escolas e secretarias municipais tiveram que se adaptar, uma vez que o procedimento se difere das compras públicas tradicionais realizadas por meio de processos licitatórios. As compras de alimentos da agricultura familiar são realizadas por Chamadas Públicas, nas quais o preço pago pelo produto é pré-determinado. Desta forma, há uma série de passos recomendados pelo FNDE para a execução do programa. A estipulação do preço a ser pago ao agricultor é feita através de pesquisa em mercado, onde são levantados os preços dos alimentos em pelo menos três vendedores varejistas locais. No caso de alimentos orgânicos, acrescenta-se $30 \%$ ao valor do convencional ou paga-se preço equivalente ao realizado no mercado local.

Outro passo importante é a articulação entre os atores sociais locais. A compra de alimentos da agricultura familiar demanda uma articulação entre os agricultores, suas organizações, nutricionistas, e diferentes setores do poder público local. Por exemplo, Procópio, Oliveira e Borsatto (2015), destacaram as dificuldades de agricultores participarem do programa pela não adequação do cardápio ao calendário agrícola.

Estudos têm apontado diferentes entraves que dificultam a operacionalização do PNAE nos municípios. Como descreveram Procópio, Oliveira e Borsatto (2015), problemas com a realização da chamada pública, cumprimento das entregas por parte dos agricultores ou o cardápio não condizente com a safra das culturas foram empecilhos para a execução do programa no município de Itapeva-SP.

$\mathrm{Na}$ realização da chamada pública, a EEx deve fornecer o máximo de elementos para que o agricultor possa participar de forma efetiva, como informações sobre preços, quantidades a serem entregues, locais de entrega e periodicidade. Baccarin et al. (2017) classificam as chamadas de acordo com os locais de entrega em: muito descentralizadas, com mais de 
50 Unidades de Recebimento (UR); descentralizadas, entre 11 e 50 UR; pouco descentralizadas, entre 2 e $10 \mathrm{UR}$; centralizadas, com 1 UR; e sem informação, quando a chamada não apresenta informação.

Souza-Esquerdo e Bergamasco (2014) evidenciaram as dificuldades encontradas para a participação da agricultura familiar no programa na região do Circuito das Frutas no Estado de São Paulo. As autoras identificaram que é baixa a adesão dos agricultores locais, tanto pela dificuldade da realização das chamadas públicas quanto pela burocracia enfrentada pelos agricultores.

Por sua vez, Triches e Silvestri (2018) evidenciaram que a falta de informações nas chamadas públicas, como o preço, logística e periodicidade, prejudicam a eficiência do programa, resultando em menor participação de agricultores familiares. Destacam ainda a importância de pesquisas que possam investigar esses entraves para tornar o programa mais eficiente na proposta de desenvolvimento local e melhoria da renda dos agricultores familiares locais.

\section{Metodologia}

A presente pesquisa foi realizada nos municípios de Angatuba, Campina do Monte Alegre e Buri (Figura 1), que possuem características socioeconômicas similares. Os três municípios estão localizados no sudoeste paulista, em uma região conhecida como Ramal da Fome, cujos municípios apresentam baixos Índices de Desenvolvimento Humano Municipal IDH-M (CEPÊDA e CARVALHO, 2016; MATHEUS, 2016). Ademais, a região se caracteriza por presença significativa de agricultores familiares que convivem lado a lado com uma agricultura altamente tecnificada. Os três municípios são de pequeno porte, com uma população variando entre aproximadamente 6.000 habitantes (Campina do Monte Alegre) e 24.000 habitantes (Angatuba).

A Tabela 1 demonstra a proporção em área e o número de estabelecimentos agropecuários por tipologia (familiar e não familiar) dos municípios estudados.

Como ponto de partida, a pesquisa empreendida levantou, sistematizou e analisou dados secundários referentes a operacionalização do Artigo 14 da Lei 11.947/2009 nos municípios estudados. Os dados analisados compreendem um período de seis anos - 2011 a 2016.

Foram analisados dados disponibilizados pelo FNDE sobre os repasses feitos aos municípios estudados para a aquisição de alimentos para a merenda escolar, bem como quais foram os valores utilizados para adquirir alimentos da agricultura familiar.

Figura 1 - Localização geográfica dos municípios de Angatuba, Buri e Campina do Monte Alegre, Estado de São Paulo.

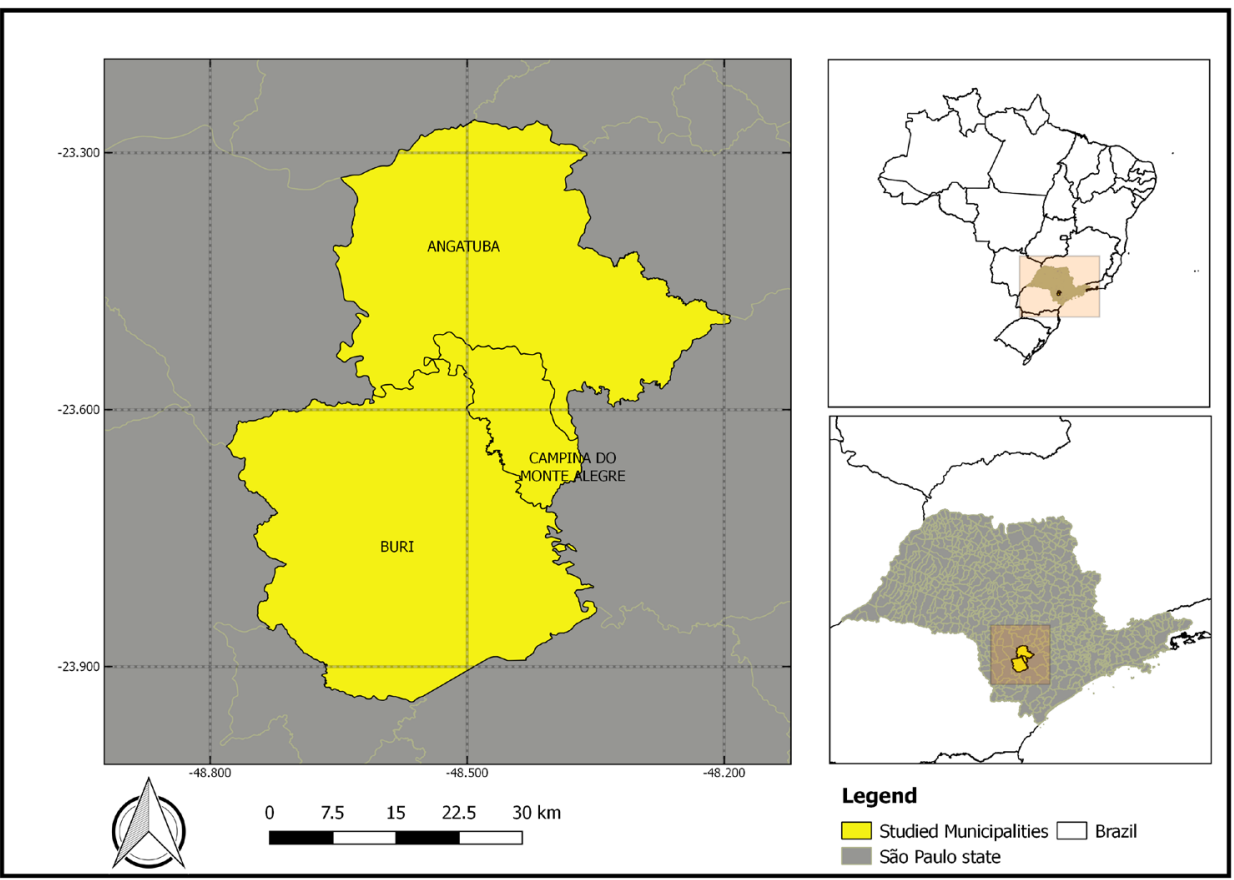

Tabela 1 - Estabelecimentos Familiares e Não Familiares nos municípios.

\begin{tabular}{llrr}
\hline \multicolumn{1}{c}{ Município } & Tipologia & Estabelecimento & \% área \\
\hline \multirow{2}{*}{ Angatuba } & Não familiar & 266 & 86,2 \\
& Familiar & 687 & 13,8 \\
Buri & Não familiar & 148 & 91,2 \\
Campina do Monte & Familiar & 245 & 8,8 \\
Alegre & Não familiar & 59 & 85,8 \\
& Familiar & 73 & 14,2 \\
\hline
\end{tabular}

Fonte: Censo Agropecuário (2006).

Ademais, foram consultados os sítios eletrônicos dos municípios estudados para a coleta de informações relacionadas às chamadas públicas realizadas.

Os dados secundários permitiram a análise da operacionalização do programa quanto aos valores repassados para os municípios e os respectivos valores gastos com a agricultura familiar, assim como permitiu a identificação das organizações da agricultura familiar que forneceram 
alimentos para merenda escolar.

Para complementar os dados secundários, durante o primeiro semestre de 2018 , foram coletados dados primários a campo por meio da realização de entrevistas semiestruturadas nos diferentes locais que atuam na operacionalização do PNAE. Dessa forma, em cada munícipio, foram entrevistados ao menos um dos agentes públicos responsáveis pelas chamadas públicas, merendeiras, nutricionistas e o responsável pela associação dos agricultores. Assim, foram realizadas ao menos quatro entrevistas por município, o que permitiu identificar os entraves da operacionalização do programa na percepção de cada ator. O Quadro 1 mostra o número de entrevistados por município.

Quadro 1- Número de entrevistados e cargos ocupados.

\begin{tabular}{|l|c|c|c|}
\hline & Angatuba & Buri & $\begin{array}{l}\text { Campina do Monte } \\
\text { Alegre }\end{array}$ \\
\hline Gestor público & 1 & 1 & 1 \\
\hline $\begin{array}{l}\text { Representante Associação/ } \\
\text { Cooperativa }\end{array}$ & 2 & 1 & 2 \\
\hline Nutricionista & 1 & 1 & 1 \\
\hline Merendeira & 2 & 1 & 2 \\
\hline
\end{tabular}

Fonte: Elaborado pelos autores.

As informações oriundas das diferentes fontes foram analisadas de forma integrada para a obtenção das conclusões apresentadas ao fim deste trabalho.

\section{RESULTADOS E DISCUSSÕES}

Em geral, os três municípios têm cumprido com a determinação de adquirir da agricultura familiar no mínimo $30 \%$ dos alimentos destinados à merenda escolar. A exceção no período analisado foi o município de Campina do Monte Alegre, que nos dois primeiros anos analisados adquiriu valor menor que o instruído legalmente. A justificativa apresentada foi a dificuldade dos gestores públicos de implementar a Lei, já que não houve preparo dos servidores públicos para tanto. Em 2016, novamente Campina do Monte Alegre não conseguiu cumprir com a meta de no mínimo 30\%, desta vez sendo justificado que o programa estava passando por melhorias para correção de falhas percebidas pelo próprio município.

A Tabela 2 apresenta o volume total de recursos repassados pelo FNDE dentro do PNAE para cada município, bem como o valor gasto com aquisições da agricultura familiar e a respectiva porcentagem.

Tabela 2 - Valores transferidos para os municípios e valores repassados para a agricultura familiar nos anos de 2011 a 2016 em Angatuba, Campina do Monte Alegre e Buri.

\begin{tabular}{|c|c|c|c|c|c|c|}
\hline \multirow[t]{2}{*}{ Município } & \multirow{2}{*}{$\begin{array}{l}\text { Ano } \\
2011\end{array}$} & \multirow{2}{*}{$\begin{array}{r}\text { Valor } \\
1 \\
\mathrm{R} \$\end{array}$} & \multirow{2}{*}{$\begin{array}{l}r \quad \text { transferido } \\
\text { pelo FNDE } \\
318.360,00\end{array}$} & \multicolumn{2}{|c|}{$\begin{array}{l}\text { Repasse para } \\
\text { agricultura familiar }\end{array}$} & \multirow{2}{*}{$\begin{array}{l}\% \text { do valor } \\
\text { utilizado para } \\
\text { AF } \\
32,67 \%\end{array}$} \\
\hline & & & & $\mathrm{R} \$$ & $104.013,00$ & \\
\hline \multirow{5}{*}{ Angatuba } & 2012 & $\mathrm{R} \$$ & $342.912,00$ & $\mathrm{R} \$$ & $116.228,22$ & $33,89 \%$ \\
\hline & 2013 & $\mathrm{R} \$$ & $390.400,00$ & $\mathrm{R} \$$ & $151.099,05$ & $38,70 \%$ \\
\hline & 2014 & $\mathrm{R} \$$ & $400.656,00$ & $\mathrm{R} \$$ & $121.744,80$ & $30,39 \%$ \\
\hline & 2015 & $\mathrm{R} \$$ & $474.978,00$ & $\mathrm{R} \$$ & $286.554,40$ & $60,33 \%$ \\
\hline & 2016 & $\mathrm{R} \$$ & $483.508,93$ & $\mathrm{R} \$$ & $296.332,01$ & $61,29 \%$ \\
\hline \multirow{6}{*}{$\begin{array}{l}\text { C a m p i n a } \\
\text { do Monte } \\
\text { Alegre }\end{array}$} & 2011 & $\mathrm{R} \$$ & $96.120,00$ & $\mathrm{R} \$$ & $3.975,65$ & $4,14 \%$ \\
\hline & 2012 & $\mathrm{R} \$$ & $102.060,00$ & $\mathrm{R} \$$ & $10.902,50$ & $10,68 \%$ \\
\hline & 2013 & $\mathrm{R} \$$ & $106.920,00$ & $\mathrm{R} \$$ & $33.397,73$ & $31,24 \%$ \\
\hline & 2014 & $\mathrm{R} \$$ & $85.840,00$ & $\mathrm{R} \$$ & $31.010,96$ & $36,13 \%$ \\
\hline & 2015 & $\mathrm{R} \$$ & $45.296,00$ & $\mathrm{R} \$$ & $21.858,25$ & $48,26 \%$ \\
\hline & 2016 & $\mathrm{R} \$$ & $130.290,27$ & $\mathrm{R} \$$ & $27.175,00$ & $20,86 \%$ \\
\hline \multirow{6}{*}{ Buri } & 2011 & $\mathrm{R} \$$ & $317.700,00$ & $\mathrm{R} \$$ & $129.242,50$ & $40,68 \%$ \\
\hline & 2012 & $\mathrm{R} \$$ & $367.944,00$ & $\mathrm{R} \$$ & $120.970,00$ & $32,88 \%$ \\
\hline & 2013 & $\mathrm{R} \$$ & $414.140,00$ & $\mathrm{R} \$$ & $131.384,83$ & $31,72 \%$ \\
\hline & 2014 & $\mathrm{R} \$$ & $318.960,00$ & $\mathrm{R} \$$ & $174.590,99$ & $54,74 \%$ \\
\hline & 2015 & $\mathrm{R} \$$ & $300.114,00$ & $\mathrm{R} \$$ & $125.816,79$ & $41,92 \%$ \\
\hline & 2016 & $\mathrm{R} \$$ & $378.569,89$ & $\mathrm{R} \$$ & $173.783,55$ & $45,91 \%$ \\
\hline
\end{tabular}

Fonte: Fundo Nacional de Desenvolvimento da Educação.

O município de Angatuba fornece alimento para aproximadamente 5.130 estudantes entre escolas municipais e estaduais, adquirindo alimentos da agricultura familiar desde 2011 e realizou chamadas públicas anuais entre 2011 e 2013. Entretanto, entre os anos de 2014 a 2016, houve apenas uma chamada realizada em 2014, a qual foi prorrogada para os anos posteriores 
e segundo os gestores não houve necessidade de novas chamadas, pois os preços estavam atualizados com o ano corrente, sendo que tanto os produtos quanto as quantidades dos mesmos se mantiveram.

Para cada chamada pública realizada ou prorrogada, somente uma organização de agricultores familiares realizou a entrega dos alimentos. Em 2011 foi uma cooperativa do município de Itapeva (100 km da sede do município), nos anos seguintes a fornecedora das chamadas foi uma associação do município de Campina do Monte Alegre da qual fazem parte agricultores familiares de toda a microrregião, mas com grande predominância de agricultores dos municípios de Angatuba e Campina do Monte Alegre.

Campina do Monte Alegre apresenta uma trajetória de participação do programa parecida com o de Angatuba. O munícipio realizou também chamadas públicas anuais entre 2011 e 2013 e entre os anos de 2014 a 2016 , houve apenas uma chamada realizada em 2014, que foi sendo prorrogada. O município tem um total de 1.396 estudantes beneficiados pelo PNAE. A organização social que fornece alimentos para o programa é originária do município, participando desde o primeiro ano da chamada, sendo a mesma que fornece os alimentos em Angatuba.

Por sua vez, o município de Buri vem realizando chamadas públicas em todos os anos. De 2011 a 2015 era uma associação de agricultores familiares do município que forneceu os alimentos, em 2016 uma associação de um município vizinho passa a fornecer em substituição à associação local, mas com participação de agricultores de Buri, sendo esses os priorizados para as entregas no munícipio. Buri possui 4.308 estudantes matriculados em escolas municipais e estaduais.

Segundo os agentes públicos dos três municípios, os valores gastos com a aquisição de alimentos para a merenda escolar vêm de duas fontes, do FNDE que é a base utilizada para a aplicação da lei, e de recursos da própria prefeitura, uma vez que o valor repassado às prefeituras é insuficiente para a aquisição dos alimentos necessários. Sendo assim, a porcentagem apresentada é referente ao repasse que é feito para as Entidades Executoras.

Os dados apontam que o município de Angatuba apresenta maior aquisição de alimentos da agricultura familiar, visto que nos anos de 2015 e 2016 mais de $60 \%$ dos recursos do PNAE foram gastos com a agricultura familiar e em nenhum ano esteve abaixo dos 30\% determinados.

Campina do Monte Alegre, por sua vez, apresentou o menor nível das porcentagens, estando no período estudado, abaixo do limite durante três anos 2011, 2012 e 2016.

O município de Buri também faz um repasse expressivo para a agricultura familiar, com valores próximos a 50\% do recurso. Segundo o Secretário da Agricultura do município, a intenção do município é aumentar gradativamente o montante adquirido através das chamadas públicas.

No estado de São Paulo, a média de aquisição dos municípios para 2016 foi de 16,04\%, onde 147 municípios adquiriram mais de 30\%; 233 não realizaram a compra mínima de $30 \%$ e outros 238 não fizeram compra alguma de gêneros alimentícios da agricultura familiar, valor que demonstra a ineficiência dos municípios na execução do programa (FNDE, 2017).

Em entrevista realizada, o responsável pelas chamadas públicas de Angatuba afirma que não houve dificuldade na implementação e execução do programa, uma vez que a associação vencedora da chamada é do município vizinho, e que muitos dos agricultores envolvidos são efetivamente de Angatuba, apesar da associação também contar com o fornecimento de agricultores de outros municípios da região. Ademais, segundo o mesmo, não houve outras chamadas públicas tanto porque os preços da chamada de 2014 estavam atualizados quanto por não haver outros agricultores ou associações na região com interesse em atender o PNAE no município. Por outro lado, a chamada pública do ano de 2018 foi prorrogada para ajuste, uma vez que os preços, até então, eram baseados em preço fixo tabelado em sites de licitações públicas. Após identificação do equívoco, a pesquisa de preços foi corretamente mudada para o levantamento de preço nos mercados locais.

O gestor municipal responsável pelo programa de Campina do Monte Alegre afirmou que a execução do programa vem ocorrendo a contento no município, sem grandes dificuldades. Ademais, explicou que o município incrementa com recursos próprios os valores gastos com a merenda escolar, sendo que esse montante é destinado exclusivamente para aquisição de alimentos via licitação, desconsiderando a agricultura familiar.

Segundo o gestor de Buri, o programa tem sido executado de forma eficiente, sem problemas na relação com os agricultores ou outros entraves, sendo todas as chamadas públicas do município ganhadas por organizações que possuem em sua maioria, agricultores do próprio município. De acordo com o Secretário de Agricultura e Meio Ambiente, muitos alimentos comprados pela prefeitura são orgânicos, porém ainda sem certificação, pois os agricultores estão em processo de certificar sua produção. O gestor municipal também revelou que a prefeitura por meio da Secretaria de Agricultura está incentivando a produção de orgânicos e que ainda não realiza a compra de $100 \%$ de alimentos orgânicos devido ao custo mais 
elevado e quantidade ainda insuficiente.

As afirmações dos gestores, em grande parte contradiz o que diferentes pesquisas têm identificado em relação às dificuldades para operacionalização da Lei ${ }^{\circ} 11.947$ de 2009. De acordo com Procópio, Oliveira e Borsatto (2015), no município de Itapeva, localizado na mesma região dos municípios estudados, há alguns entraves relacionados à Lei e falta de planejamento das organizações que não conseguem estabelecer a capacidade de produção, fazendo demorar a realização das chamadas públicas. Paula, Kamimura e Silva (2014) demonstram que em Mineiros, Estado de Goiás, a dificuldade se deu a partir da criação da cooperativa para comercialização, o processo demorou cerca de dois anos até que os agricultores pudessem comercializar.

Informação ressaltada pelos gestores públicos de forma unânime foi a importância para a economia local do programa, pois os recursos recebidos para a alimentação escolar ficam, ao menos em parte, no próprio município.

Por serem municípios de pequeno porte, é fácil o diálogo entre o poder público local e os agricultores, o que facilita a execução do programa. Entretanto, é possível notar certo nível de inconsistência por parte dos gestores, uma vez que em dois dos municípios foi realizada apenas uma chamada pública nos últimos anos, impossibilitando a entrada de novos agricultores ou organizações.

Outro ponto que facilita a participação dos agricultores familiares no programa diz respeito a logística demandada para a entrega dos alimentos. Em todos os municípios pesquisados as entregas ocorrem de forma centralizada e uma vez por semana. Baccarin et al. (2017) identificaram que isso reduz os custos para o agricultor, uma vez que várias entregas na semana aumentam consideravelmente os custos.

O gestor da associação vencedora das chamadas públicas de Angatuba e Campina do Monte Alegre identifica como a principal dificuldade na participação no programa, a entrega dos produtos. Segundo ele, atender a merenda escolar requer maior organização na produção e na entrega, assim ele afirma que muitos agricultores preferem permanecer apenas no PAA e acabam não participando do PNAE por receio de não cumprir o contrato. Nessa linha, Camargo et al. (2013) identificam a participação no PAA como uma primeira inserção no mercado institucional e uma preparação para o PNAE, sendo que este último requer maior planejamento da produção por parte dos agricultores.

Ainda segundo o gestor da associação o calendário de entrega dos alimentos também é um fator que inibe e dificulta a participação dos agricultores. O entrevistado expôs que o cardápio é planejado pela nutricionista das prefeituras sem articulação ou consulta prévia aos agricultores, muitas vezes desrespeitando o calendário agrícola. Esta situação causa, constantemente, a necessidade substituição dos alimentos que foram colocados no cardápio por outros que os produtores estejam produzindo. Isto dificulta a logística da associação, sendo que o próprio gestor afirma que muitas vezes tem de realizar a compra desses produtos em Centrais de Abastecimento para atender as demandas municipais, fato que foge do escopo da Lei $n^{\circ} 11.947$. Para minimizar esse problema, a associação ampliou o seu quadro de agricultores familiares para a participação de agricultores de outros municípios do Estado de São Paulo e não somente de Angatuba e Campina do Monte Alegre, principalmente para o fornecimento de frutas.

Buri, por sua vez, apresentou boa relação entre os atores, e os entraves ficaram apenas relacionados ao valor do repasse do FNDE ao município, valor esse que limitava a compra de alimentos da agricultura familiar, especialmente os orgânicos.

Outro ator fundamental para a execução correta do programa são as nutricionistas, pois é este profissional quem determina os cardápios e consequentemente as demandas de aquisição de alimentos. A nutricionista de Angatuba alegou que possui boa comunicação tanto com a prefeitura municipal como com a entidade executora e com os agricultores. Porem, os gêneros alimentícios para as chamadas públicas são decididos pela nutricionista sem a consulta prévia aos agricultores, o que muitas vezes acaba por demandar alimentos não disponíveis na região, limitando o volume passível de ser comercializado pelos reduzindo a capacidade de absorção da renda por agricultores locais.

Em Buri, segundo a nutricionista do município existe boa comunicação entre os diferentes agentes locais. A Secretaria de Agricultura e Meio Ambiente apoia a nutricionista e o setor de compras do município na elaboração das chamadas públicas, bem como intermedia a relação com os agricultores. Essa boa comunicação tem reduzido as divergências entre os produtos constantes nas chamadas e os disponíveis na região. Semanalmente são feitos os pedidos dos gêneros alimentícios à associação vencedora da chamada, que prioriza os agricultores do município para a entrega. Somente quando não há oferta local é que são entregues por produtores do município vizinho, Capão Bonito.

A responsável pela formação do cardápio das escolas de Campina do Monte Alegre disse que possui contato com os agricultores, mas que precisa ser melhorado, para tanto a Secretaria de Agricultura e Meio Ambiente 
afirmou que está realizando um trabalho para melhorar a comunicação entre as partes envolvidas e a qualidade dos alimentos.

O valor do repasse do FNDE segundo as três nutricionistas entrevistadas é um fator limitante para a aquisição de mais produtos, uma vez que o valor repassado por aluno é insuficiente para a diversificação e aquisição de muitos dos produtos que são produzidos regionalmente.

Uma informação que se destacou na pesquisa foi a opinião das merendeiras das escolas que foram entrevistadas em Campina do Monte Alegre. Segundo as entrevistadas o principal problema do programa diz respeito à qualidade dos produtos fornecidos, sendo que muito é desperdiçado ou perdido por estar fora dos padrões aceitáveis de uso. As merendeiras de Angatuba não relataram esse problema, mesmo sendo a mesma associação que fornece para ambos os municípios, destacando que os produtos que não atendiam à qualidade esperada eram substituídos por outros, e usaram como exemplo um agricultor que foi substituído do fornecimento pela constante entrega de alimento sem a qualidade mínima exigida. Um importante fator a ser melhorado, segundo as merendeiras entrevistadas, diz respeito a um maior rigor na recepção dos alimentos, que deveriam apresentar melhor qualidade. Ademais, elas recomendam que deveria haver um contato mais direto entre elas e os agricultores, o que facilitaria a resolução de muitos dos problemas identificados.

Por outro lado, a merendeira entrevistada em Buri alegou que a qualidade dos alimentos é o principal fator a ser destacado, complementando que muitas vezes são alimentos orgânicos. Esses alimentos são entregues na Casa da Agricultura do município onde passam por avaliação da qualidade juntamente com a nutricionista e o Secretário de Agricultura e Meio Ambiente, dessa forma, a comunicação sempre é realizada diretamente com $o$ agricultor que entrega o produto.

Foi unânime entre as merendeiras entrevistadas a percepção de que há significativa importância a aquisição de gêneros alimentícios da agricultura familiar para a economia local.

\section{CONSIDERAÇões FINAIS}

Apesar de no período compreendido pela pesquisa dois dos três municípios estarem cumprindo com a legislação utilizando ao menos $30 \%$ da verba repassada pelo FNDE com alimentos oriundos da agricultura familiar local, a pesquisa de campo evidenciou que algumas distorções vêm ocorrendo, ou mesmo que peculiaridades na operacionalização podem provocar impacto nos resultados esperados do programa.

Nos municípios de Angatuba e Campina do Monte Alegre, verificouse que nos últimos anos apenas uma associação comercializou gêneros alimentícios para o PNAE. Ademais, a mesma associação entregou alimentos durante três anos, tendo sido realizada apenas uma chamada pública. Entretanto, os gestores públicos, em nenhum momento relataram terem a percepção do baixo alcance de agricultores em relação ao montante de agricultores familiares no município.

Por serem municípios de pequeno porte, a proximidade dos agricultores com os gestores públicos locais é um fator que facilita a operacionalização do programa, principalmente pós chamada pública. Os problemas identificados tanto pelos agentes públicos quanto pelos agricultores são rapidamente solucionados; por exemplo, a substituição de alimentos fora de padrões de qualidade é facilmente realizada. Exceção fica a cargo de Campina do Monte Alegre, onde há desperdício de alguns produtos devido à baixa qualidade.

Um problema suscitado pelo gestor de uma das associações foi o receio de agricultores em participar do programa devido a sua burocracia, preferindo entregar os alimentos para o PAA. Uma melhor preparação dos gestores e nutricionistas reduziria esse entrave no programa.

Conforme pôde ser observado no decorrer na pesquisa, as chamadas públicas nem sempre levam em consideração as especificidades da agricultura familiar local, o que causou a necessidade da associação de agricultores familiares adquirir produtos em centrais de abastecimento para o cumprimento do contrato, fato que distorce a real intenção de fortalecimento à produção e comercialização em circuitos curtos baseados na agricultura familiar. Como destacado pelo gestor da associação, esse problema poderia ser resolvido com maior diálogo entre Entidade Executora e agricultores e suas organizações.

Aponta-se que nos municípios estudados existem outros grupos de agricultores familiares que poderiam atender às demandas da merenda escolar, porém por falta de conhecimento dos agricultores e de interesse do poder público local, esses grupos não participam do programa.

Outro fato que chamou a atenção foi a opinião das merendeiras entrevistadas de um dos municípios, que reclamaram de baixa qualidade dos alimentos fornecidos pela associação. De forma diversa ao previsto no PNAE, os estudantes estão consumindo alimentos de que muitas vezes passaram do ponto ideal de consumo e com aspecto duvidoso. Tornase necessário apontar, que muitas vezes a qualidade do alimento não necessariamente está relacionada à sua aparência, pois apesar de possuir 
uma aparência fora dos padrões estabelecidos, tal fato pode não influenciar a qualidade do produto.

Por outro lado, foi unânime entre os entrevistados a percepção de que é importante a aquisição de gêneros alimentícios da agricultura familiar para a economia local.

Devido ao tamanho dos municípios estudados, seria relativamente fácil promover encontros entre os agricultores, nutricionistas e merendeiras para que esses diferentes atores compartilhassem suas expectativas; fato que não ocorreu até o hoje.

Longe de se fazer ilações acerca dos gestores públicos locais ou das associações de agricultores familiares, o que se percebe é que houve até o presente momento um relativo descompromisso em potencializar as oportunidades oferecidas pelo programa. Contraditoriamente, todos os atores entrevistados consideram que vem executando o necessário para que a lei seja cumprida.

Por se tratar de um programa de política pública que envolve vários setores da sociedade, o programa é complexo e exige maior atenção por parte dos executores, dessa forma a participação de mais de uma secretaria dos municípios aumenta a eficácia do programa, como no caso de Buri, que apresentou menores entraves devido a boa interação dos diversos atores sociais.

Sem questionar a relevância de se promover políticas públicas para a agricultura familiar, o que esta pesquisa evidencia é que se não houver engajamento dos atores locais, os resultados esperados pelos formuladores das políticas e dos programas podem ficar muito aquém do esperado, e aparecerem distorções nos processos de operacionalização que fogem dos escopos definidos.

\section{Agradecimentos}

Os autores agradecem a todos os entrevistados por compartilharem seu tempo e informações.

Este trabalho foi finaciado pelo processo 427726/2016-6, Conselho Nacional de Desenvolvimento Científico e Tecnológico; e o primeiro autor foi apoiado nesta pesquisa por uma Bolsa PIBIC/CNPq/UFSCar.

\section{REFERÊNCIAS}

BACCARIN, J. G. et al. Indicadores de Avaliação das Compras da Agricultura Familiar para Alimentação Escolar no Paraná, Santa Catarina e São Paulo. Revista de Economia e Sociologia Rural, v. 55, n. 1, p.
103-122, jan. 2017.

BALSADI, O. V. Programa de Aquisição de Alimentos da Agricultura Familiar: os primeiros resultados obtidos em 2003. Informações Econômicas, v. 34, n. 5, 2004

BRASIL. Lei 11.947 de 16 de junho de 2009. Dispõe sobre o atendimento da alimentação escolar e do Programa Dinheiro Direto na Escola aos alunos da educação básica; altera as Leis nos 10.880, de 9 de junho de 2004, 11.273, de 6 de fevereiro de 2006, 11.507, de 20 de julho de 2007; revoga dispositivos da Medida Provisória no 2.178-36, de 24 de agosto de 2001, e a Lei no 8.913, de 12 de julho de 1994; e dá outras providências. Disponível em: <http://www.planalto.gov.br/ccivil_03/_ato2007-2010/2009/lei/111947. htm>

Ministério da Educação. Fundo Nacional de Desenvolvimento da Educação. Resolução/CD/FNDE $\mathbf{n}^{\circ}$ 25, de 4 de julho de 2012. Altera a redação dos artigos 21 e 24 da Resolução ${ }^{0}$ 38, de 16 de julho de 2009, no âmbito do Programa Nacional de Alimentação Escolar (PNAE). Diário Oficial da República Federativa do Brasil, Brasília, DF, 5 jul. 2012. Disponível em: $<$ http://www.fnde.gov.br/acesso-a-informacao/institucional/ legislacao/item $/ 4610$-resolu $\% \mathrm{C} 3 \% \mathrm{~A} 7 \% \mathrm{C} 3 \% \mathrm{~A} 30$-cd-fnde-n $\% \mathrm{C} 2 \% \mathrm{BA}-25$,de-14-de-junho-de-2013>.

CAMARGO, E. A. DE O. M. DE et al. Programa de Aquisição de Alimentos (PAA) como Instrumento de Fortalecimentos de Assentamentos Rurais: O Caso do Assentamento 23 de Maio, Estado de São Paulo. Informações Econômicas, v. 43, n. 1, p. 18-28, 2013.

CEPÊDA, V. A.; CARVALHO, J. G. Diagnósticos Socioeconômicos dos Municípios de Buri e Campina do Monte Alegre. São Carlos: Ideias Intelectuais e Instituições - UFSCar, 2016.

FNDE - FUNDO NACIONAL DE DESENVOLVIMENTO DA EDUCAÇÃO; Dados da Agricultura Familiar. Brasília-SP, 2017. Acessado em: 29/05/2018 Disponível em: <http://www.fnde.gov.br/programas/pnae/ pnae-consultas/pnae-dados-da-agricultura-familiar $>$. 
GRISA, C.; ZIMMERMANN, S. A. Estado e Sociedade Civil na Promoção da Segurança Alimentar e Nutricional no Brasil: a Construção do Programa de Aquisição de Alimentos da Agricultura Familiar (PAA). Agroalimentaria, v. 21, n. 41, p. $17-36,2015$.

KAGEYAMA, A. A.; BERGAMASCO, S. M. P. P.; OLIVEIRA, J. T. A. DE. Uma tipologia dos estabelecimentos agropecuários do Brasil a partir do censo de 2006. Revista de Economia e Sociologia Rural, v. 51, n. 1, p. 105-122, 2013.

MALUF, R. S. et al. Nutrition-sensitive agriculture and the promotion of food and nutrition sovereignty and security in Brazil. Ciência \& Saúde Coletiva, v. 20, n. 8, p. 2303-2312, 2015.

MATHEUS, D. Análise da relação da política dos territórios da cidadania e a ação do capital no campo: o caso do território da cidadania do Sudoeste Paulista. [s.1.] Unesp, 2016.

PAULA, M. M. DE; KAMIMURA, Q. P.; SILVA, J. L. G. DA. Mercados institucionais na agricultura familiar: dificuldades e desafios. Revista de Política Agrícola, v. 23, n. 1, p. 33-43, 2014.

PROCÓPIO, F. DE C.; OLIVEIRA, J. T. A. DE; BORSATTO, R. S. As dificuldades para a participação de assentamentos rurais no Programa Nacional de Alimentação Escolar (PNAE): o caso de Itapeva/ SP. Retratos de Assentamentos Rurais, v. 18, n. 1, p. 361-382, 2015.

ROCHA, C. Developments in national policies for food and nutrition security in Brazil. Development Policy Review, v. 27, n. 1, p. 51-66, 2009.

SOUZA-ESQUERDO, V. F. DE; BERGAMASCO, S. M. P. P. Análise sobre o acesso aos programas de políticas públicas da agricultura familiar nos municípios do circuito das frutas (SP). Revista de Economia e Sociologia Rural, v. 52, n. 1, p. 205-222, 2014.

TRICHES, R. M.; SILVESTRI, F. Adequação das Chamadas Públicas para Aquisição de Produtos da Agricultura Familiar para a Alimentação Escolar. Desenvolvimento em Questão, v. 16, n. 44, p. 233-259, 2018.

\section{OS LIMITES, DESAFIOS E POTENCIALIDADES DA AGRICULTURA FAMILIAR NO PNAE EM MUNICÍPIOS ATINGIDOS PELA MINERAÇÃO}

Tayrine Parreira Brito

Viviane Guimarães Pereira ${ }^{2}$ Adriano Pereira Santos ${ }^{3}$

ReSumo: O artigo é resultado de pesquisa desenvolvida nos municípios de Alvorada de Minas, Conceição do Mato Dentro e Dom Joaquim (MG), localizados na área de influência direta do Projeto de mineração Minas-Rio. Considerando que a situação da agricultura familiar tem se agravado na região com os impactos do projeto de mineração e também que o Programa Nacional de Alimentação Escolar (PNAE) com a implementação da Lei ${ }^{\circ}$ 11.947/2009 tem sido uma das possibilidades de incentivo e valorização da agricultura familiar, o objetivo deste trabalho foi compreender a execução do PNAE nos três municípios e identificar quais são os desafios, limites e potencialidades da participação da agricultura familiar no programa. Tratase de uma pesquisa interdisciplinar de abordagem qualitativa, realizada por meio de entrevistas semiestruturadas e pesquisa documental. Os resultados indicam o PNAE como uma política importante para a agricultura familiar, mas com limitações e desafios à participação dos (as) agricultores (as) atingidos (as) pelo projeto minerário Minas-Rio.

Palavras-chave: Política Pública; Alimentação Escolar; Organização Produtiva; Desenvolvimento Rural.

${ }^{1}$ Mestra em Desenvolvimento, Tecnologias e Sociedade pela Universidade Federal de Itajubá (2018).E-mail: tayrinepb@gmail.com

Unersidade Federal de Itajub́, participa do Programa de Mestrado dm Desenvolvimento, Tecnologias e Sociedade (Dtecs/Unifei).E-mail: vgpereira@yahoo.com.br

${ }^{3}$ Professor Adjunto do Instituto de Ciências Humanas e Letras (ICHL), da Universidade Federal de Alfenas (Unifal-Mg).E-mail: adriasantos81@gmail.com 